\title{
Multidisciplinary teams and line management
}

\author{
Practical problems and areas of conflict in clinical psychiatry
}
Som D. Soni, Consultant Psychiatrist, Hope and Prestwich Hospitals, Eccles Old Road, Salford, M6 8HD (correspondence); LeONARD STEERS, Mental Health Adviser, City of Salford Social Services, Crompton House, Chorley Road, Swinton, Salford M27 2BP; TONY WarNe, Unit Nurse Manager, Prestwich and Hope Hospitals, Bury New Road, Prestwich, Manchester M25 7BL; and W. H. SANG, Unit General Manager, Prestwich Hospital

Recent developments in psychiatry have required increased inter-disciplinary collaboration to ensure co-ordination of specialist skills. Simultaneously, changes in management structures of participating disciplines have produced vertically organised systems of management with multiple tiers often referred to as line management. The membership of multidisciplinary teams (MDTs) now comprises individuals at varying levels in management hierarchy and with different abilities to contribute to the decision making process. Managers usually impose attitudes, expectations and obligations on staff working in MDTs which are often major obstacles to effective teamwork by causing ambivalence and opposing loyalties leaving individual workers in invidious positions (Fagin, 1985). This paper reviews current thinking on multidisciplinary teams and present day management structures among disciplines in psychiatry and discusses the practical problems and areas of conflict resulting from their interaction in settings where MDTs are expected to operate.

\section{Multidisciplinary teams}

MDTs have been advocated as the most appropriate method for delivery of health care in psychiatry and more particularly in the area of community mental health (CMH) (Furnell et al, 1987; Ramon, 1989). Many advantages are claimed for teamwork in clinical psychiatry (Øvretveit, 1986): it is assumed to provide a better co-ordination of different disciplines, a clearer and more equitable division of labour within the team, a holistic approach to the development of therapeutic plans for patients, a stimulating environment for team members where each can contribute to his/her optimal ability thereby inculcating team spirit and mutual support among team members. In practice, however, such lofty ideals are rarely, if ever, achieved.
It is intuitively clear that many different forms of MDTs exist depending on the nature of collaboration required. The term network is sometimes employed to indicate informal, often ill-defined arrangements where members of different disciplines meet on an ad hoc basis in order to discuss and resolve mutual problems. Formal teams, however, imply recognition by management, regularity of meeting arrangements, agreement on explicit objectives with a structure to match, adequate administrative and clinical co-ordination and perhaps a defined geographical or operational base. At least four types of teams have been described (Øvretveit, 1986):

(a) managed teams have one individual (the manager) who is fully accountable for all case work decisions

(b) integrative, or 'democratic' teams in which there is no leader with formally agreed authority or accountability

(c) co-ordinated teams where one member assumes the role of a team co-ordinator with powers to organise casework and to negotiate

(d) core teams which are full-time and fully managed by the team leader and are implemented where two or more professions have considerable overlap in their work. Many different permutations and combinations of these basic structures exist in practice depending on the functions of MDTs: clinical teams (ward rounds, assessment meetings, case conferences, clinical reviews), planning teams, management teams, discussion forums etc.

Internal tensions and external pressures that work against successful MDT functioning are well documented (Dingwall, 1980). Thus all members face the vexed questions of accountability and leadership (Øvretveit, 1986), relative case autonomy and consensus decision-making often produces internal strife which increases with the size of the team (Furnell et al, 1987), unmet administrative needs pose problems 
of dealing with external bureaucracies (Noon, 1988) and interpersonal difficulties result in formation of cliques and covert power struggles (Ramon, 1989). Other difficulties include loss of individual identity through blurring of roles and professional boundaries (Borus, 1978), and inappropriate deployment of group or individual resources resulting in disenchantment and disintegration of team structure (Noon, 1988). A less well appreciated problem is that the team approach may remove from clients options which are rightfully theirs and from clinicians, decisions they might think appropriate but are diluted or vetoed through the team's deliberations. Much work and time has to be expended in maintaining the cohesiveness of the team by harnessing the constructive forces in teamwork. In one centre visited by the authors, $40 \%$ of staff time was spent in administrative and staff group activities and only $25 \%$ in activities directly related to patient care. In another review of jointly funded projects, an average of 140 hours were spent by staff on management per year per person (Vaughan, 1989).

Many reviews of MDTs within the framework of CMH in United States revealed a disappointing state of affairs with "regression into a decentralised type of custodial care, blurring of boundaries and priorities degenerating into false egalitarianism" (Borus, 1978). This resulted in denial of care to the very patients who were most in need of it such as the chronically mentally ill whose plight in asylums initiated the community psychiatry movement in the first place. Although many model and successful programmes have been developed, attempts to find commonalities amongst them have not been successful and most have not been reproducible in other settings either completely or in part.

\section{Line management}

The original management structure, with the matron and ward sisters as key figures in nursing management at hospital level, was found outdated and inadequate with the establishment of National Health Service. The Salmon Committee, set up to reorganise the nursing services, decided to distinguish 'administrative' from 'managerial' functions, setting up in the process a multiple tier system in which the top six grades were to assume managerial and administrative roles. The Mayston report extended this to the community and reinforced the concepts of line management with a strictly vertical management structure, each level of management entrusted with distinct and defined roles effectively separating clinical and administrative nurses in a "military style" (sic) hierarchy (Fagin, 1985). The separate lines of management for hospital and community sectors have resulted in distinct philosophies in relation to MDTs with greatest adherence to their ethos in the community producing significant conflict and diffculties particularly in CMH. In one district, ideological leanings of a nursing officer resulted in community nurses being allocated to primary health care teams, divorcing them completely from psychiatric services: subsequent departure of the nurse manager produced major organisational problems.

A similar structure has evolved with respect to social work management (Bamford, 1982) where at least four grades are interposed between the director of social services and social workers in the field who between them are responsible for statutory services such as child care which still takes precedence, and community or hospital based social work (Seebohm report). The hierarchical structure was further tightened by the Birch report and the uniquely bureaucratic response of management to public criticism in successive child care inquiries (Bamford, 1982). The separation of social work teams from health service into the sphere of local authority has resulted in considerable friction between the two arms of social welfare, with diverging philosophies and poor coordination. The publication of the Barclay report has not altered the traditional management structures. It is noteworthy that few social work departments have identified teams whose priority is delivery of care in mental health.

Psychology services, after evolving into a major diagnostic and therapeutic discipline, have stressed their relative independence. A system of management requiring several tiers from top grade through principal, senior and basic grade levels has developed based on traditional civil service lines. The development of occupational therapy into an independent profession has been followed by establishment of a firm system of management where all major policy decisions are left to the middle and top level managements within each district. The management structure of both these professions are at present under review. Only the consultant psychiatrist lacks this line management both in clinical and in planning/ administration; junior doctors rarely participate in true MDT settings except perhaps on the wards or under supervision.

\section{Problem areas}

\section{Decision making}

MDTs, by their nature and composition, include members from horizontally as well as vertically organised professions. One result of this is that the consultant psychiatrist is often required to collaborate with staff in other professions who are in intermediate' ranks and in some ways are more comparable to junior medical staff. Psychology and social work, as independent disciplines, do, in a limited way, distinguish between a professional who can act with a 
degree of independence and one who acts under clinical supervision. In reality, whereas doctors, and to some extent psychologists, can make decisions based on available information, this can sometimes be diffcult for others, especially if their decisions have nonclinical implications. In these circumstances, the decisions may be delayed until they have been referred to and instructions filtered back from higher levels of management. Alternatively, the individual could show initiative and make a decision only to find it questioned by his superiors. Although MDTs can be carefully constructed to ensure individuals are matched for their status and influence in the organisation, in practice, this is not always feasible and is, therefore, a rare occurrence.

\section{Lines of communication}

A parallel problem relates to the delays in dissemination of information between tiers of organisation. This delay can often result in some members being excluded from crucial aspects of MDT functioning. Deferment of decisions is commonplace in multidisciplinary administrative meetings. Hierarchical structure may also lead to dissemination of misinformation leading to misunderstandings and improper implementation of policies. We have sometimes noticed different versions of a decision being passed on to members of the team through their respective lines of communication, leading to conflicts at MDT meetings. Thus when senior management, after discussions, decided to implement a policy allowing consultants in mental handicap to admit patients to acute wards, erroneous communication to ward staff resulted in consultants being refused a bed until the managers had been approached, which was not always possible in emergencies. Effective communication in any large organisation is problematic; paradoxically, the existence of MDTs, because of their need to respond rapidly to events, may serve to identify and highlight these problems.

\section{Supervision/performance reviews}

Line managers in vertical organisations are expected to provide supervision, and hold performance reviews, to monitor individual members of the MDTs. These are dictated by the policies and orientations of the unit managers which often differ for different disciplines and may also be in conflict with the philosophies of the MDT. Not infrequently, decisions following these reviews, are made and implemented without recourse to discussions with other members of the team, resulting in changes over which individual team members have little control. The consequent friction can occasionally result in problems, sometimes even disintegration of the MDT and the service which the team provided. In one instance, after a performance review by area social services, the social workers were advised to withdraw from the community MDT and provide only advisory service, despite protestations by the team and the social workers concerned, which resulted in the clinical team being dismantled. Another example of this was seen when senior nurse managers reorganised community nursing services without consulting other health professionals or even the nurses themselves, resulting in a spate of grievances; within days the decision was reversed.

\section{Staff appointments}

The appointment of team members is normally performed by line managers and there is no requirement on their part to consult or to ask other team members to participate in the appointment process, which requires careful attention to the need for compatibility between members of the MDT and whether the appointee has the required training qualifications and/ or skills useful in the context in which the MDT would be functioning. Appointments to the team before it is commissioned are often left too late and much valuable time may be wasted because the members have been unable to resolve individual conflicts which are innate in the process of working together. Frequently, pressing needs in other areas result in line managers imposing alterations in membership of the team, resulting in significant upheavals in team equilibrium and dynamics.

\section{Staff training}

It is reasonable to assume that at the time of the establishment of the team, training of members would be integrated with its needs and philosophy and allocation of resources made, so that the team is properly equipped to deal with the problems it is expected to tackle. Often people are appointed by the line managers without cognisance of the needs of the team. Once appointed, many then get sent off to training courses, again without consultation, resulting in a team that is depleted for prolonged periods. Even if initially the training is taken into account, frequent changes of personnel by line management, often unrelated to career moves by team members, produce significant unsettling effects. The opening of one community mental health centre (CMHC) was delayed for over four months because of these problems and, when opened, faced severe shortages for a long time because the issues mentioned above were not considered.

\section{Clinical/managerial distinction}

In many vertically organised management structures, there is a clear demarcation between clinical and managerial posts. This is perhaps most obvious in nursing where nurses, who are otherwise clinically 
competent, are compelled to relinquish ward or community based jobs in order to improve their remuneration and career prospects and move into non-clinical managerial posts for which they may be ill-equipped ('Peter principle') or have little enthusiasm. If many nurses who acquire experience in patient care move into managerial positions, the result must necessarily be a dilution of patient care since only the more junior or the less able nurses are left to deliver service. There are no rewards in present day health organisations for experience and/or excellence in clinical practice other than 'personal or job satisfaction'. It is not unknown in clinical psychiatry for wards to experience a rapid turnover of senior nurses for reasons of such career moves. Another drawback of this distinction between clinical and managerial posts is that decisions which may impinge directly on patient care are sometimes made outside MDT settings, often by individuals with little contact or knowledge of patients who would be affected by them. Not infrequently, consultation has been lacking and decisions introduced without adequate briefing. Poor grading systems and/or their improper implementation often compound these problems associated with lack of proper career structures in clinical services; this was most vividly seen during the recent nurse grading exercise prompted by the 1989 pay review where complaints and grievances occurred in almost every hospital in the country.

\section{Budgetary controls}

Most MDTs have no control over resources which are normally administered by line managers. CMHCs are particularly vulnerable to these influences since the staff are expected to provide not only clinical care, but also to organise the unit on an operational basis. In addition, the current climate requires that their work be evaluated and the results incorporated into their work practices. The structure within health authorities is directed towards identifying personal accountability for financial control thus militating against 'team budgets'. As such, therefore, managers are loathe to devolve any budgetary control to those who are 'on site'. One jointly funded $\mathrm{CMHC}$ had to function without stationary and toilet rolls for several months because the local authority and health service managers could not agree on the source of this funding!

\section{Comment}

Many of the factors that contribute to failure of MDTs in clinical psychiatry relate to the structure, establishment and other factors which are largely intrinsic to the heterogeneous nature of clinical organisation of delivery of service in psychiatry. Extrinsic factors such as inadequate funding of physical and manpower resources, and political and non-political controls over the team etc are also relevant. Both have been extensively reported and are not the subject of this communication which focuses on the problems that exist at the interface between line managements' attitudes, expectations and actions and the MDTs.

Hierarchical managements are not without virtues: they provide clear lines of accountability, give authority to those in the top tiers and are comprehensible to most individuals (Bamford, 1982). On the other hand, they create a sense of distance between management and 'workers' which is further aggravated by burgeoning bureaucracy and marked pay differentials. In addition, the several tiers through which decisions have to filter and the need for extensive liaison with other disciplines with similarly convoluted management systems predisposes these organisations to processes which result in decisions that are not always concordant with individual facets of patient care particularly in areas, such as community mental health, where working with other professions is essential. The tighter the control of management over its hierarchy, the greater the difficulties: an extreme case is the requirement in some social work departments that all correspondence be channelled through the directors of social services (Bamford, 1982)!

It is possible that the problems described in this paper may not necessarily be a direct result of hierarchical management systems but due to inappropriate implementation of administrative procedures. To some extent, these conflicts are inevitable; line managers have to manage within a much wider context where many different aspects of service delivery and prioritisation often result in decisions which conflict with the functioning of the team. Thus for nurses, needs of the hospital may have to be weighed against the needs of the community, for social workers, needs for statutory requirements such as child care against community mental health etc. Perhaps a major reason for these conflicts is poor appreciation by management and MDTs of the needs of a heterogenously constituted team and the insidiously damaging effects of dual accountability and divided loyalties.

Several measures could ensure that the pernicious effects of interaction between line management and MDTs are minimised. In a dynamic system such as MDT, where a delicate equilibrium is required to sustain its constructive potential, a continuous system of feed-back and monitoring is essential starting from when it is first conceived. It is now accepted that all MDTs should have formal statements of policies which are decided in advance and reviewed regularly so as to accommodate any change that may occur in time. The respective roles of line managers and the extent of their control over the team or its members 
should be clearly defined; this is one aspect of current operational policies that is sadly overlooked. Arrangements for regular review of the team with a small viable group of managers from different disciplines must be enshrined in the policy document before the team is commissioned. There is some appreciation in social services of the needs of MDTs as evidenced by appointment of staff facilitators who supervise and help teams establish themselves; what their eventual impact will be is at present unclear.

The problem areas catalogued in this paper also suggest measures that can be instituted once the team is established. Line managers should develop and use rapid and formal as well as informal channels of communication. The presence of a project manager is now considered a necessity for the proper functioning of the team (Vaughan, 1989) and he/she should be regularly involved in any changes that are initiated from either side. Line managers must consider the training needs and their costs before accepting any proposals for establishing MDTs and they must take into account the recurrent costs of in-service training in financial terms and in terms of effects on service. The present arrangements where appointment of staff is conducted without consultation with the team produces instability and disequilibrium; appointments should be made early and in good time, transfers without consultation kept to a minimum and replacements arranged as rapidly as possible. Performance reviews and regular supervision are an essential part of effective management; their institution and results could be more open and collaborative so that decisions about patient care are not adversely affected. Clinical decisions should be left to the deliberations of the team. In CMHCs, some degree of devolution of budgetary control is essential if they are to have the autonomy required for proper functioning in the community and independence from the stifling effects of rigid hierarchical control.

The position of individual members of the team in the complex relationship between MDT and line management is difficult and poorly defined. For clinical decisions relating to patient care, members of the teams are clearly responsible to the team leader; in non-clinical matters, they would be answerable to their line manager. There is, however, an area of overlap where difficulties arise; in these situations, it is essential that individual team members are not placed in situations where divided loyalties are in conflict with the essence of shared responsibilities in the team. The consultant has an important role to play (Rawnsley, 1984) in CMH and more specifically in MDTs: much evidence suggests that his sapiential leadership, as a result of his rigorous training, extensive experience in patient care and the specific legal and clinical responsibility for patients makes him a pivotal figure in the team. He also has a degree of independent authority, unfettered by rigid hierarchical controls, to negotiate on matters relating to the team.

\section{References}

BAMFORD, T. (1982) Managing Social Work. Tavistock Library of Social Work Practice. London: Tavistock Publications.

BORUS, J. F. (1978) Issues critical to survival of mental health. American Journal of Psychiatry, 135, 1029-1035.

Dingwall, R. (1980) Problems of teamwork in primary care. In Teamwork in the Personal Social Services and Health Care (eds S. Lonsdale, A. Webb \& T. L. Briggs). London: Croom Helm.

FAGIN, L. (1985) Community Mental Health Centres and Community Mental Health Teams: Tackling the Issues. Home Affairs Workshop. London: King's Fund Centre.

Furnell, J., Flett, S. \& Clark, D. F. (1987) Multidisciplinary clinical teams: some issues in establishment and function. Hospital and Health Services Review, January, 15-18.

Noon, M. (1988) Teams: the best option? Health Services Journal, October, 1160-1161.

ØVRETVEIT, J. (1986) Organisation of Multi-disciplinary Community Teams. Uxbridge: Health Services Centre, Brunel University.

RAMON, S. (1989) Mental health social work: the state of the art. Social Work Today, 16 June, 16-17.

RAWNSLEY, K. (1984) The future of the consultant in psychiatry. Bulletin of the Royal College of Psychiatrists 8, 122-123.

VAUGHAN, P. (1989) Matrix management: Managing together. Insight 11 April, 12-14.

A full list of references is available from $\mathrm{Dr}$ Soni. 